\title{
Traditional and non-conventional medicines: the socio-anthropological and bioethical paradigms for person-centred medicine, the Italian context
}

\author{
Paolo Roberti di Sarsina $\cdot$ Ilaria Iseppato
}

Received: 2 May 2011 / Accepted: 19 July 2011 /Published online: 11 August 2011

(C) European Association for Predictive, Preventive and Personalised Medicine 2011

\begin{abstract}
In Italy the use of non-conventional medicines (NCM) is spreading among people as in the rest of Europe. However, in Italy, unlike that in other countries of the European Union, at the present time the juridical/legal status of NCM is not well established, mainly due to the lack of any national law regulating NCM professional training, practice and public supply and to the absence of government-promoted scientific research in this field. This is an obstacle to safeguarding the patient's interests and freedom of choice, especially now that dissatisfaction with biomedicine is inclining more and more people to look for a holistic, fairer and person-centered form of medicine.
\end{abstract}

Keywords Non-conventional medicine legal status .

Person-centered medicine - Mainstream medicine .

Complementary and alternative medicine $\cdot$ Health-genesis .

Pharmacoeconomy

P. Roberti di Sarsina

Expert for Non Conventional Medicine, High Council of Health,

Ministry of Health,

Rome, Italy

P. Roberti di Sarsina

Observatory and Methods for Health,

Department of Sociology and Social Research,

University of Milan-Bicocca,

Milan, Italy

\section{Iseppato}

University of Bologna,

Bologna, Italy

e-mail: ilaria.iseppato@gmail.com

Present Address:

P. Roberti di Sarsina $(\varangle)$

Via Siepelunga, 36/12,

40141 Bologna, Italy

e-mail: paolo.robertidisarsina@unimib.it

\section{Some points of terminology}

The World Health Organization has long called non-conventional medicine "Traditional Medicine" in deference to the countries where such forms of healing are in the long-standing cultural heritage: one thinks of China and India.

The term adopted by the Cochrane Collaboration and the international literature is actually "Complementary and Alternative Medicine" (Consensus Conference, United States Office for Alternative Medicine of the National Institutes of Health, Bethesda, USA, 1997); one immediately infers that this has a multiple sense, covering treatments chosen exclusively, i.e. as first-choice therapy (alternative medicine), or second-choice therapy, i.e. in combination with others (complementary medicine). Traditional and non-conventional medicine is the commonest term in Italian usage, which we shall be adopting for various reasons: it is less charged with ideology, hence more neutral scientifically; it is a dynamic and relative description of medicines which should not be seen as inferior to conventional medicine. These are the forms that are currently excluded from the official line-up of the health service and from teaching in the medical faculty. "Nonconventional" is here synonymous with "unorthodox", "different" from biomedicine.

For these reasons we prefer to stick to "non-conventional medicine" (NCM) for the Italian setting. It is socially more widespread, better known, understood in common Italian parlance, used by the FNOMCeO in its Terni Document (2002), by the European Parliament (1997) and the Council of Europe (1999), used again in the Consensus Document on NCM in Italy (2003). Besides, the term NCM ties up with the fact that such disciplines are not properly included as obligatory subjects on an Italian degree course in medicine or veterinary science, unlike the practice of 
various other countries. For the World Health Organization (WHO) the terms "complementary medicine", "alternative medicine" or "unconventional medicine" are interchangeable with "traditional medicine" and embrace the broad set of disciplines that do not form part of a particular country's tradition or part of the dominant health system, as in Italy. The WHO thus deliberately uses "unconventional" to suit countries (like Italy) where these branches of medicine and relative health systems are not on any obligatory degree syllabus or part of mainstream national health. The WHO insists that it is proper and ethical to preserve, protect, promote, study, pass on and apply the cultural heritage enshrining medical knowledge and anthropological health systems whether western or eastern, in complete respect of the original integrity of the traditional paradigms and patrimonies [1,2].

Again, on 8th November 2008 at the World Congress on Traditional Medicine held in Beijing, the WHO drew up the "Beijing Declaration on Traditional Medicine" calling, among other things, for "action and cooperation by the international community, governments, and health professionals and workers, to ensure proper use of traditional medicine as an important component contributing to the health of all people, in accordance with national capacity, priorities and relevant legislation".

The WHO plea for protection and promotion of anthropological health systems in their original form was confirmed on 16th November 2010 by the General Assembly of UNESCO (United Nations Educational, Scientific and Cultural Organization) which included traditional Chinese Acupuncture and Traditional Chinese Moxibustion (two of the best known branches of Traditional Chinese Medicine) in the List of Mankind's Intangible Immaterial Heritage.

\section{Diffusion of non-conventional medicine in Italy: the background}

The demand for NCM is growing rapidly among the people of Europe. In financing the CAMbrella Consortium as part of its Seventh Framework Programme (FP7), the European Union has acknowledged the vital need for a holistic approach in public health. Thus, the European Parliament has included an item on NCM under the heading "Health, optimising the delivery of health care to European citizens" in the Seventh Framework Programme for Research and Development (2008-2013).

Traditional and non-conventional medicines are needed to foster and maintain good health in Europe's young and old population: they are not only effective but very safe. It is now commonly accepted at home and abroad that traditional and non-conventional medicine has come to play a permanent innovative role in public health. This is also shown by the mounting theoretical and practical interest being shown by the university, hospitals and district health care.

A number of such academic experiences correspond to the first concrete signs of Italian traditional and nonconventional medicine getting established: affording, that is, a sustainable democratic alternative for individual and communal health, enabling people to choose how to stay healthy and break out of the previous cultural straitjacket (emancipation).

On the 21st August 2007 ISTAT came out with data from its latest multi-purpose survey on "Non-Conventional Therapies in Italy". The survey refers to 2005 when it took a sample of some 60,000 families. The macroscopic finding was that $13.6 \%$ of the Italian population (about eight million people) said they had used traditional and nonconventional medicine in the three prior years. Homeopathy led the field among the various traditional and nonconventional medicines. A pronounced connection was still found between higher education and use of such treatments. And significantly, 5 years on from the previous ISTAT report (1999) at least eight million Italians vouched for the efficacy of their therapy choice.

Another relevant point concerns the economic cost to the family. The constant erosion of the mean purchasing power these last few years is making it tougher to stick to a non conventional treatment course (cost of the doctor, medicines and adjuvant therapy). This is entirely borne by the family purse, except in the case of workers with an independent health fund (like journalists, upper management and others) that refunds such treatment. (The statistics confirm that these professional categories are amongst the biggest users.) It is more and more common to find parents giving up their treatment and only spending on their children's.

On 15th October 2008 the CENSIS Foundation (Center for Social Investment Studies) - a socio-economic research institute founded in 1964 - released the results of its Forum on Biomedical Research as regards Italian public health. Where traditional and non-conventional medicine is concerned, $23.4 \%$ of Italians had used alternative treatment over the previous year, a figure not much lower than 2001 which recorded $23.6 \%$.

The latest EURISPES finding for Italy 2010 is that $18.5 \%$ of the population use NCM.

The data that follow $[3,4]$ neatly bear out the social role that NCM has increasingly come to play in Italy, where it is now a full-blown "bio-political category".

- ISTAT (1996-99): 9 million Italians use NCM (15.5\%)

- ABACUS (2003): 30\% of Italians are familiar with the term traditional and non-conventional medicine

- DOXA (2003): $23 \%$ of the population use NCM 
- ISPO (2003): $65 \%$ of the population are familiar with the term traditional and non-conventional medicine and know something about it

- FORMAT (2003): $31.7 \%$ of Italians have used NCM at least once; $23.4 \%$ use NCM regularly

- CENSIS (2003): 50\% think NCM useful; over 70\% claim it should be passed by the National Health Service; $65 \%$ would like more monitoring by the national health authorities

- Menniti-Ippolito et al. (2004)-3-year follow-up on 52,332 families (140,011 persons): $15.6 \%$ use NCM (homeopathy $8.2 \%$, manual therapy $7 \%$, phytotherapy $4.8 \%$, acupuncture $2.9 \%$, other NCMs $1.3 \%$ )

- ISTAT (2005): 8 million Italians use NCM (13.6\% of the population)

- EURISPES (Rapporto Italia 2006): 10.6\% of the population choose NCM

- CENSIS (2008): $23.4 \%$ had recourse to NCM in the previous year (especially homeopathy and phytotherapy)

- EURISPES (Rapporto Italia 2010): more than 11 million opt for NCM, i.e. $18.5 \%$ of the population

- Health Monitor CompuGroup Medical-II Sole 24 Ore Sanità (2011): about 52\% of general practitioners suggests homeopathic therapies to patients.

There are over 20,000 Italian doctors who prescribe homeopathic and anthroposophic medicines. Many are MDs and Veterinarians who have completed years of specific post-graduate training in homeopathy, anthroposophic medicine or homotoxicology.

Homeopathic and anthroposophic medicines are only found at the chemist's, though this extends to virtually all Italian chemists; over 5,000 medicines are on offer.

The Italian homeopathic sector has some 30 active companies employing over 1,200 persons.

In 2007 about 300 million euros was spent on treatment by homeopathic and anthroposophic medicinal products in Italy, which ranks third on the European market after France and Germany. The sector has continued to grow at an average of $6-7 \% / \mathrm{yr}$ over the last decade.

By VAT, IRES and IRAP the State levied 40 million euros in 2007. Since neither homeopathic treatment nor the homeopaths prescribing it cost the country anything, the homeopathic sector brings the Italian State an active net revenue of $€ 40,000,000$ - not counting the saving in doctors' consultation costs.

That the Italian population are choosing traditional and non-conventional Medicine is thus a consolidated fact and it is time the health institutions opened their ranks, coming into line with resolutions by the European Parliament (1997) and the Council of Europe (1999), and adopting the WHO (2002) strategic plan on NCM. This would mirror what has happened in other countries of Europe and worldwide, where some traditional and non-conventional medicines are an integral part of health systems, dispensed by the public health service and reimbursed by private insurances.

\section{Legal status of non-conventional medicine in Italy}

The National Federation of Councils of MDs and Dentists (FNOMCeO) has taken pains to define its own position on NCM by a process of professional and social comparison which culminated in May 2002 with a motion by the National Council at Terni. Nine years, therefore, have elapsed since the FNOMCeO National Council-in light of Resolution $\mathrm{N}^{\circ} 75$ of the European Parliament 29 May 1997 (29, 30-34) and Resolution No 1206 of the Council of Europe 4 November 1999 "On the status of unconventional medicines"-recognized nine traditional and non-conventional medicines for their social relevance: Acupuncture, Traditional Chinese Medicine, Ayurvedic Medicine, Homeopathic Medicine, Anthroposophic Medicine, Homotoxicology, Phytotherapy, Chiropractic and Osteopathy.

In Italy chiropractic and osteopathy are primary health disciplines and, as such, independent and distinct from the field of medicine. Hence practicing chiropratic or osteopathy does not constitute abuse of the doctors' or physiotherapists' profession. All rulings to date have fully confirmed this view (see among other rulings that of the Genoa Court 23 July 2003, published in Diritto Penale e Processo 8/2004, pp. 1003-1013). Chiropractic and osteopathy may also be practiced by doctors provided they have undergone the internationally established training for the two disciplines. The Register of Chiropractors was opened at the Italian Labour, Health and Social Policy Ministry under art. 2, comma 355, of Law $N^{\circ}$ 244/2007. Though not yet implemented, this gives the discipline of Chiropractic a profile in line with the WHO policy for safe practice of the profession and in keeping with legislation in other European countries where Chiropractic has long been regulated. The aforesaid article requires a specific five-year degree in chiropractic and defines the chiropractor as a primary health professional freely entitled to practice.

These nine traditional and non-conventional medicines were acknowledged as falling under the exclusive professional responsibility of a doctor or dentist, as being "to all effects and purposes medical practice" (FNOMCeO guidelines on non-conventional medicines and practices, Terni, May 18th 2002).

The Doctors' Professional Code in force since 2006 (in this respect like its predecessor from 1988) devotes an 
article (art. 15 in 3 paragraphs) to traditional and nonconventional medicine.

Article 15 runs:

- Non-conventional practices must not lack the decorum and dignity of the profession and are only to be performed under the direct and non-delegable professional responsibility of a doctor

- Non-conventional practices must not impede the citizen from having specific scientifically established treatments and always requires his/her informed consent

- The doctor may not engage in any form of collaboration or enable third-party non-doctors to practice in the said area of non-conventional medicine.

The medical profession's highest ruling body lays down that the only persons entitled to practice are doctors and dentists who have gone through rigorous specific training. To guarantee protection of citizen health the FNOMCeO both upholds the principle of freedom to treat and calls on doctors rigorously to observe the Professional Code especially in informing patients fully and correctly and in getting their informed consent that they are not being routed away from treatment of proven effectiveness. NCM may only be practiced under the direct professional responsibility of the doctor without faculty of delegation; the doctor is also forbidden to engage the help of outsiders. This puts its finger on the key issue: it is doctors pure and simple who practice these forms of medicine; nor is it one non conventional medicine but a series of non-conventional medicines which are often lumped together as "different" by ill-informed mainstream medicine.

In 2003 the National Federation of Veterinarians (FNOVI) issued a similar document in which five disciplines are recognized as veterinary practice (Acupuncture, Traditional Chinese Medicine, Homeopathic Medicine, Homotoxicology, Phytotherapy). The Veterinary Professional Code likewise devotes an article (art. 30 in 2 paras) to traditional and nonconventional medicine. Article 30 runs:

- Non-conventional medicines within the veterinary sphere are exclusively to be practiced by veterinary surgeons

- Professional duty and dignity must be upheld in this practice which falls exclusively under the professional's direct and non-delegable responsibility, once appropriately informed consent has been obtained from the client.

In its bid to foster professional quality and hence the efficiency, adequacy and safety of the doctor and dentist's practice, the FNOMCeO 2002 Document urges Parliament to translate the document's principles into appropriate normative form so that public health may work towards genuine pluralism in this world of globalization and movement of populations [5-9].

In 2003, as soon as a Consensus Document on NCMs in Italy was signed, a Permanent Consensus and Coordination Committee for NCM in Italy was set up in the presence of the then vice-president of FNOMCeO [10]. The Committee is open to all health units and respective medical centres of representation, to the national, regional and local Institutions of the Republic and to citizen associations to safeguard NCM and promote recognition thereof according to the Terni Document.

On 12th December 2009 the FNOMCeO National Council approved a document entitled "Training guidelines in non-conventional medicines and Practices reserved for MDs and Dentists". Out of the 2002 list there remain: Acupuncture, Traditional Chinese Medicine, Ayurvedic Medicine, Homeopathic Medicine, Anthroposophic Medicine, Homotoxicology and Phytotherapy.

The Supreme Court of Appeal (1982, 1999, 2003, 2005, 2007) has ruled that acupuncture is a medical act, that whoever prescribes homeopathic products must be a doctor; that it is an infringement of medical powers for anyone without a degree in medicine to practice traditional and non-conventional medicines. The Supreme Court made it clear once and for all that public health is to be safeguarded by the rule that all traditional and non-conventional medicines be practiced by doctors alone. Practice of this profession is therefore subordinate to public registration of the qualifying exam result and enrolment on the professional Roll, preceded by attainment of a degree in medicine.

The Constitutional Court $(2005,2006,2007,2008)$ has ruled that the Regions may not legislate to create professional profiles or new rolls, which is reserved for the State; thus they may not legally frame new health profiles that are not defined and recognized by a prior national law. On the question of whether regional legislation regulating professional activity is constitutionally legitimate, the Constitutional Court ruled that the regions' legislative power on matters to do with "professions" must abide by the principle whereby the State, with its necessarily Unitarian character, shall define all professional figures and their respective profiles and qualifications of entitlement, while it is the Regions' task to oversee such areas as bear specifically on the regional set-up. This principle holds as a general limit on the powers of regional law, over and above any particular application to individual norms. In the present instance this rules the submitting of regional laws to approval by the Law Judge (35-47) to be constitutionally illegitimate.

The new plan for CME was presented at the First National Conference on CME held at Cernobbio on September 14-15, 2009. The document approved by the Conference linked State, Regions and the Autonomous 
Provinces of Trento and Bolzano. The new plan devotes a specific chapter to "Reference Non-conventional Medicines and Practices" which reads: "When the provider presents a training plan containing events falling under Non-Conventional Medicines, the accrediting board shall assess such NCM events individually to see if they fit in with the training targets indicated. For training purposes Phytotherapy, Homeopathic Medicine, Homotoxicology, Acupuncture, Ayurvedic Medicine and Anthroposophic Medicine are exclusively reserved for the professions of doctor, dentist, veterinary and dispensing chemist as part of their professional duties. For any other training areas falling under Non-Conventional Medicine but different from the above list yet figuring in the provider's training plan, that plan shall be submitted by the accrediting board to the National Committee for Continuing Training for its compatibility to be ascertained." Inexplicably, given that the National Committee for Continuous Training in Medicine which drew up the new $\mathrm{CME}$ programme is vice-chaired by the FNOMCeO, the list of disciplines fails to include Traditional Chinese Medicine although this is on the classification drawn up by the FNOMCeO National Council in 2002 and that of the Document approved by the National Council in 2009.

That the Italian National Federation of Councils of MDs and Dentists (FNOMCeO) should occupy the central position stems from a kind of syncretism among the contending viewpoints of biomedicine and non conventional medicine which interact on three different planes: politically, organizationally and epistemologically. It is epistemology that paves the way for redefinition of the biomedical paradigm for, without it, the mainstream health system would make the mistake of reducing traditional and non-conventional medicines to a mere appendage of biomedicine. The truth is that mainstream biomedicine can only cope with the present and future by changing its own epistemological formulation towards a personalized, prohealth, anthropological, humanistic and bio-psycho-spiritual approach which is the common denominator of traditional and non-conventional medicine.

A "dual liberty" thus needs to be recognized-the individual's and the doctor's right to choose the avenue of therapy-answering as this does to the spirit of article 32 of the Italian Constitution. Part of such recognition still awaits Parliament's approval of a national framework law on traditional and non-conventional medicine as well as the green light on the high-level training program.

That traditional and non-conventional medicine has come to occupy a stable innovative position in public health is now fully established and accepted at home and abroad. This is proved first by the mounting recourse to NCM throughout Europe and the world (in Italy eleven million Italians choose NCM), and second by the growing theoretical and practical interest being shown in the area by the university, hospital and general healthcare system across the European Union. In 2007 to her great credit, the then Health Minister Senator Livia Turco first included NCM among the subjects for the Experts on the Italian High Council of Health (back in the days of the 15th Legislature). After a chapter of failures, Parliament tried again in the 16th Legislature to regulate the position of NCM country-wide: the Commission for Health of the Senate appointed Sen. Daniele Bosone, MD, to coordinate a unified Bill governing nonconventional medicines as practiced exclusively by doctors, dentists and vets.

Although the Medicines listed by the FNOMCeO have gone through various stages of Parliament, there seems to have been little positive feedback in the medical world. This has meant that patients - often nursing prejudices of their own-have tended to find out about the range of treatments off their own bat, while under-informed GPs have been equally caught up in prejudice-some for and some against-without pondering the very real risks that such inbuilt prejudice entails.

Against a twenty-year backdrop of Parliament failing to ratify a score of variously proposed bills to regulate the position, in all this time it is only private training organizations that have conducted post-graduate medical training in Italy.

Although use of NCM has remained at the 'grass roots' level of patient initiative, the academic institutions would have ample opportunity, did they so wish, to promote new initiatives in the NCM field: for under-graduate and postgraduate education they could draw on the hundreds of qualified private training instructors to provide patients and health officials with reliable information, leading to more evidence-based therapy strategy and the generation of new knowledge, and meanwhile improving the results of medicare in terms of drug economics and a sustainable equilibrium.

However, we desire to highlight that for the academic year 2011-2012 will be activated the post-graduate Master's Course in "Health Systems, Traditional and Non-Conventional Medicine" in collaboration with the Observatory and Methods for Health, University of Milan-Bicocca (directed by Prof. Mara Tognetti) and the Association for Person-Centered Medicine Charity, Bologna (chaired by Paolo Roberti di Sarsina, MD; http://www.medicinacentratasullapersona.org).

The Master Course (the first of its kind in Italy) aims to provide participants with tools of knowledge and analysis on the realities of health systems, taking into account the evolutionary dynamics of inclusion and increasing range of Traditional and Non Conventional Medicine. The Master Course aims to provide useful tools of theoretical and practical training of professionals capable of integrating 
economic and management aspects with those related to clinical care and medicines, as well as the relational paradigm.

The Master Course is aimed at graduates in medicine but also in economics or humanities. It will give powers to tackle the issue of health, person-centered medicine, traditional and non-conventional medicine and health systems based on anthropological models, through an overview of health and its impact on welfare.

We hear complaints in all quarters that funds are lacking to set in motion any proper organic integration strategy. Meanwhile patients of every social extraction and with all manner of pathologies are using NCM on a daily basis, despite the most fragmentary or even non-existent information as to how far NCM has penetrated the medical and academic world.

Law 3/2001 modified clause V of the Constitution and thereby launched federalism, since when healthcare has been profoundly regionalized in terms of planning and resource management. This has given the Regions a more central role vis-à-vis government and parliament. The changes to clause $\mathrm{V}$ involved redefining the duties of the Ministry and the Regions: we no longer have the Ministry regulating and the Regions adjusting accordingly, but principles laid down by the State, and Regional laws to implement them. In the years since the Constitution was changed the two levels have had difficult relations, mainly because the Ministry in daily practice has found it hard to adjust its role so that the Regions have constantly been obliged to assert their powers.

To avoid further regional fragmentation, we clearly need a national law confirming that all non-conventional medicines, without any form of demagogic discrimination, are fully recognized on an equal footing. This will properly extend the constitutional right to choose freely among, and have equal access to, NCM treatments. The freedom to choose entails being fully informed as to the various possible diagnostic and therapy approaches, as well as having full access to the medicines used by the various branches of NCM.

Any such legislation must be based on precise definition of the criteria accreditation procedures for trainees, free from all conflict of interest, as well as the training curricula: rules need drawing up to govern professional practice and authorize nonconventional drugs, remedies and prophylaxis.

The economic sustainability of integration becomes a problem in its own right, if one notes the discrepancy between essential levels of medicare guaranteed to all citizens - clearly defined as a basic point of healthcare uniformity - and essential levels of social assistance - still completely lacking [11].

Pending inclusion of NCM practices in the National Health service, it is hence indispensable we redefine the criteria for accessing essential levels of such assistance. At present the whole idea of health as a right guaranteed to every human being seems in jeopardy. This is partly due to breakdown of the "social contract" drawn up between modern biomedicine and western society over a century ago: we will attend to social medicine and you can enjoy a monopoly in the health field.

Now that biomedicine is faltering and unable to keep its side of the bargain, the other contractual party - the State and the society it represents-seems minded to challenge the original contractual obligation.

\section{Non-conventional medicinal products: what Italian law says}

In 2006, Italy was apprised of the European Directive on Drugs 2004/27/CE which contains five specific articles on homeopathic and anthroposophic medicines expressly covering the manufacturing peculiarities of, and control over, those two kinds of pharmaceutical product. Italy's own legislation on homeopathic and anthroposophic medicines is embedded in Legislative Decree $N^{\circ} 219$ of 24 April 2006, implementing Directive 2001/83/CE (and subsequent changes thereto) which seeks a community code on medicines for human use, as well as in Directive 2003/94/CE. This legal position would later be modified by Legislative Decree $N^{\circ} 274$ of 29 December 2007 "Norms correcting Leg. Decree $N^{\circ} 219$ of 24 April 2006 implementing directive $2001 / 83 / \mathrm{CE}$ as concerns a community code on medicines for human use"; it appeared in the Gazzetta Ufficiale as $\mathrm{N}^{\circ} 38,14$ February 2008.

Article 20 of leg. Dec. N ${ }^{\circ}$ 219/2006 states that "when described in an official pharmacopoeia and prepared according to a homeopathic method, anthroposophic medicines are classed by the present decree as comparable with homeopathic medicines".

The effect of receiving that directive was that at least homeopathic and anthroposophic medicines were rendered legitimate by the Italian government until 2015. Inexplicably, a number of rules safeguarding the citizenry still remain to be passed. For example, the law still exists in Italy whereby packets may not display any indications or dosages - a serious hardship for the consumer.

Incredibly, again, for many years new homeopathic medicines have not been authorizable: ever since 1995 the administrative procedure for registering new drugs has been in abeyance. What is more, all forms of publicity on homeopathic remedies are banned, which is further evidence of discrimination.

Traditional and non-conventional medicine provides the National Health System with substantial social and economic advantages: remedies usually cost less than conven- 
tional medication for the same illness; compared with the high incidence of iatrogenic damage associated with taking allopathic medicine, homeopathic and anthroposophic medicines have no side effects, which greatly reduces the social cost (work and study hours lost); the innocuous nature of the remedy limits the need for expensive checks and monitoring devices; and in being typically simple to manufacture, homeopathic and anthroposophic medicaments do not have any environmental impact.

The EU directive dates from 2006: Italy still has to give the green light on registering new homeopathic and anthroposophic medicaments. The drift of the law here is to bring Italy into line with the rest of Europe on new categories; homeopathic and anthroposophic products pre-eminently belong under this description. The delay will inevitably slow down market and research development, as well as blocking employment opportunities. In dragging its feet over authorizing this step, Parliament runs the risk of a fine from the European Union. In practice the AIFA (Italian Drug Agency) simplified procedure for registering homeopathic and anthroposophic medicines as prompted by the European Directive is at a standstill. In the domestic pharmaceuticals sector homeopathic and anthroposophic sales have considerable weight in terms of turnover and employment, and should be allowed to work at full speed, especially in an economic situation like the present in Italy. The fact is that, though used all over the world, homeopathic and anthroposophic medicaments cannot currently be prescribed on the Italian 'national health'. European drug law demands that this intolerable situation be resolved before it bounces back on patients and hamstrings an entire sector - third on the European market, as we said. It is hard to understand, therefore, why Italy is still dragging her feet over simple implementation of the European directive.

In March 2009 the Italian Drug Agency, in charge of authorizing release of drugs onto the commercial market, gave guidelines for simplified registration of homeopathic and anthroposophic medicines (Homeopathic medicaments: Information to be given on Form 3 of the CTD dossier of homeopathic and anthroposophic medicaments). By contrast, the Italian regulating board has so far not faced the issue of traditional Chinese and Indian medical productsgiving proof of short-sightedness way beyond the caution of the European Medicine Agency (ex EMEA) which has formed an ad hoc work group.

\section{Europe rethinks its line on non-conventional medicine}

In 2004 two action platforms on NCM were set up in Europe: the European Research Initiative on Complemen- tary and Alternative Medicine, EURICAM (Vienna) to get CAM included in the Seventh Founding Program, and the European Forum on Complementary and Alternative Medicine, EFCAM (Brussels).

In 2005 Brussels hosted the European Open Health Forum for Stakeholders "Health Challenges and Future Strategy" where the plenary session tabled (and then presented to the European Commission) the following motion on NCM: "we tackled issues like setting patient needs as an action priority within EU health policy, and protecting patients from threats to their health.

If one realizes that:

- there is a growing demand for traditional and nonconventional medicine among Europe's citizens;

- in clinical effectiveness traditional and non-conventional medicine $\mathrm{s}$ are often as effective as conventional medicine, as is widely shown by many long-lasting studies on thousands of patients;

- Traditional and non-conventional medicine $\mathrm{s}$ are not only effective but very safe;

- Traditional and non-conventional medicine can thus be of concrete help in reducing the enormous morbidity and mortality caused by adverse effects of allopathic medicines, the time has come for the European Union to include traditional and non-conventional medicine in its sphere of action" (Brussels, 08.11.05).

On 23 October 2007 the European Parliament and Council jointly espoused the Decision (N. 1350/2007/EC) to set up a Second Community Action Program on Health (7th Framework Program of the European Community for research, technological development and demonstration activities 2008-2013-abbreviated as FP7) [12]. For the first time ever, an item was included on traditional and nonconventional medicine. In so doing the EU institutions somehow recognized traditional and non-conventional medicine (in conformity with the 1997 and 1999 resolutions). We here give the English version of the text from the Official Gazette of the European Union: "the Program should recognize the importance of a holistic approach to public health and take into account, where appropriate and where there is scientific or clinical evidence about its efficacy, complementary and alternative medicine in its actions".

Once the European Commission launched a specific area for NCM in EU nations within the third call for FP7, a platform was set up in Berlin linking institutions fostering NCM in EU countries (to which Italy's Committee for NCM belongs): this program "FP7-CAMbrella" is to present a major European project for research into various branches of NCM (the 3rd call for theme 1 "Health" of the specific FP7 work program 'Cooperation' includes under section 3.1 a research topic on complementary and alternative medicine, topic 3 ). 
The research group has 16 members representing as many scientific partner organizations from 12 nations of the European Union.

The members of FP7 CAMbrella Pan-European research network for complementary and alternative medicine (CAM) are:

- Wiener Internationale Akademie für Ganzheitsmedizin (Austria)

- Universitetet i Tromsø (Norway)

- Universität Bern (Switzerland)

- University of Southampton (UK)

- Charitè Universitätsmedizin Berlin (Germany)

- Universität Zürich (Switzerland)

- Comitato Permanente di Consenso e Coordinamento per le Medicine Non Convenzionali in Italia (Italy)

- Karolinska Institutet (Sweden)

- Université Paris 13 (France)

- Servicio Andaluz de Salud (Spain)

- Agenzia Sociale e Sanitaria, Regione Emilia-Romagna (Italy)

- Pécsi Tudományegyetem, University of Pécs (Hungary)

- Universitatea de Medicină şi Farmacie "Victor Babeș", Timişoara (Romania)

- Syddansk Universitet (Denmark)

- Bayerische Forschungsallianz GmbH (Germany)

The Rechts der Isar Center for Research into Complementary and Alternative Medicines from Munich's Technische Universität is coordinating the Consortium. This coordination role will be critical in setting up a network of European institutes researching into non-conventional medicine, and fostering international collaboration over research in this field.

The CAMbrella Consortium is to last 3 years from January 1st, 2010. The name "CAMbrella" hints at an umbrella of research projects covering all aspects of Non Conventional Medicine. The research will be performed by workgroups each with a specific brief: from epistemology to terminology, the legal set-up for implementing NCM health care, the legal and normative status, patients' needs, the role of CAM treatments within health systems, and research methods. The goals are: to set up a Europe-wide network of first-rate NCM center with a view to creating research liaisons; to establish a terminology accepted throughout Europe to describe NCM practices; to create the basic knowledge to enable us to understand patient demand for NCM on the present scale; to review the current legal status and the policies governing provision of NCM treatment in the European Union; to explore EU citizens' needs, beliefs and attitudes where NCM is concerned.

In order to comply with the European Commission's brief the consortium has been organized into independent yet interrelated work packages whose members are to meet periodically. The whole operation is being run by a Coordinator and steered by a Scientific Steering Committee composed of the workgroup coordinators with support from an Advisory Board. The Advisory Board is made up of the main Stakeholders: patients, consumers, professionals, pharmaceutical manufacturers. The aim is thus to develop a broad overview of the current state of NCM in Europe to serve as a starting point for future research activity. At the end of the 3 years the CAMbrella Consortium will put out scientific publications on its website and a final conference will draw up a list of recommendations for the European Commission in prioritizing research and getting NCM included in health and social policies across the European Union.

On 8th November 2008 the first European Congress for Integrative Medicine in Berlin, promoted by the Institute for Social Medicine, Epidemiology, and Health Economics of the Charité University Medical Center, Berlin, set up the European Chapter of the International Society for Complementary Medicine Research, ISCMR. At the same Berlin venue 2008 also saw the birth of a European Information Center on Complementary and Alternative Medicine, EICCAM.

At the European Open Health Forum 2008, organized in Brussels by the European Commission (General Directorate for Health and Consumer Protection) the following motion on NCM was signed on 11th December 2008 for presentation to the European Commission: "Non-Conventional Medicine (CAM, Complementary and Alternative Medicine, according to the definition adopted by the Cochrane Collaboration following the Consensus Conference at the National Institute of Health, Bethesda, USA) is to be considered an absolute priority for EU health policy, bearing in mind that such medical and health practices may be chosen as an Alternative to allopathic medicine, i.e. as a first-choice therapy, or as complementary to allopathic and biomedical treatment. The fact is that:

- The demand for NCM by European citizens is steadily on the increase

- This reflects the citizens' need for personalized, holistic treatments

- About $70 \%$ of the European population uses traditional and non-conventional medicine therapies

- In clinical effectiveness traditional and non-conventional medicines are often as effective as conventional medicine, as is widely shown by many long-lasting studies on thousands of patients

- The safety and effectiveness profile of traditional and nonconventional medicine is a positive one, especially in individualized patient-centered treatment

- The techniques for manufacturing non-conventional medicaments respect and safeguard the environment 
- Including traditional and non-conventional medicine right from primary care may help reduce the cost and the enormous problem of mortality and morbidity caused by side effects from much allopathic medication

- Traditional and non-conventional medicine is in demand to foster and maintain good health in Europe among both the young and the elderly population

- Traditional and non-conventional medicine has a big contribution to make in fostering health

- In the interest of all the citizenry we strongly urge the European Union to promote inclusion of complementary, alternative and traditional medicines in its health policy".

\section{Thoughts on a person-centered medicine: recommendations and outlook}

The ups and downs of biomedicine in this era of crisis and uncertainty bring new opportunities for reflection and action to all who insist on viewing health as a key to understanding the new social landscape that is materializing at the dawn of the twenty-first century. It is true that Cartesian and Enlightenment reductionism has enabled medicine to make extraordinary progress; but in confining itself to this partial vision, medicine has tended largely or completely to fragment and objectify the classificatory processes, forgetting that human beings are made up of thoughts, emotions, beliefs, faiths, feelings, ideals, past experience and spirituality: forgetting, therefore, that a human existence does not unfold in a sequential manner.

Awareness of this enables us to analyze the changes afoot within the health organizations and networks. The process of democratization which is deranging this order set in with the eighties and nineties; the first to be affected is the patient, who finds he no longer stands subordinate to the doctor but can share some of the power and responsibility. Tardy though this revolution is compared to other walks of social development (politics or the economy, for example), it does highlight the subjective condition of patients, their values, forms of representation, preferred lifestyles and models of good health. The figure of the expert is accordingly tending to change into one who holds some of the answers and should ideally stand by and advise as the patient chooses from among the options. For as the branches of knowledge ramify, so the specialists multiply; many or more than one of them will need consulting in any single case and a middle course steered among the differing information.

At this point biomedicine began to lose its ascendancy over the emerging non-conventional medicines, or rather anthropological systems of medicine; the doctor's word was challenged in the face of the various professions interacting to solve the health problem; his authority was shaken in the eyes of the patient who more and more began to seek second opinions, parallel practices and remedies.

As the wind of pluralist democracy has swept through the health system, there has also been a far from negligible redistribution of power between the sexes: not just among doctors, but in all the ranks of the health profession the traditional gender differences are changing and seem sometimes to have reversed. And yet, for all the increased standing of citizen and patient, non-medical professions, civil associations and movements, the price of democracy and pluralism has been a certain fragility and risk attendant on the new edifice which should not be underestimated.

Safeguarding people's health, making treatment personal, human and sustainable, presupposes that the patient be central in choosing the therapy. Society has changed its perception of quality in medicine and is demanding that institutions humanize medicine: it must be both humanistic and scientifically-based, hence person-centred medicine. Diagnosing and treating each human being requires that we find an individual centre of gravity taking the whole of the person into consideration, their intrinsic unity, physical and mental: the incessant interaction of these levels forms the spiritual core of the human being, a unicum to be interpreted before it can be cured [13, 14].

Person-centered medicine conduces to individual psychophysical equilibrium which is the basis of any sustainable equilibrium in any society, present or future. Personcentered medicine is an expansion of medical knowledge and practice, not just in therapeutic but in health-genesis terms towards a genuine sociology of health, owing to its inclusive, not exclusive, nature, its systemic effectiveness which is just the opposite of the reductional, materialist approach à la Descartes. For these reasons, it is something more than a personalized approach.

Certain key points emerge from this argument. One is the gap between a classic "healthcare system" and a "pro-health system" of the kind needed to re-program public health in the teeth of worldwide economic crisis. The traditional health system does not cover the full implications of health: there are so many significant factors that must be embraced by a pro-health system. It is imperative that we integrate and liaise among the various approaches to medicine as an art; a synergy must be struck between biomedicine and anthropological or traditional and non-conventional medicines, if we are to achieve a sustainable equilibrium and contain the cost of drugs. Our lands are more and more peopled by migrants with complex needs and different health expertise. The social environment affects psychological processes which reflect in turn on our biology in the well-known "social health gradient". It may not be possible to eliminate hierarchies altogether from modern society, but the consequences can be offset in their varying forms: after 
all, the "health gradient" is not just confined to the poorer countries or the socially indigent. One's position on the social ladder only becomes health-impairing if one is deprived of certain opportunities connected with needs that everyone's wellbeing depends on: a say in how one lives, a chance to participate socially, a chance to meet one's basic health needs - there being no true liberty without emancipation. "Gender health" is a real issue, connected to which sex one belongs to. Above all society needs a humanized medicine, lower iatrogenic side effects, respect for people's right to choose their pathway to care. We need more and more accurate information, given the paltry number of large-circulation biomedical journals containing clinical information of relevance to doctors. Together with a heightened ethical sense, we need to be able to count on the reliability of scientific publications (the giant health industry channeling most of our health resources may dangerously cramp the autonomy and even results of research). It is no longer enough to learn about the origins of pathology; traditional and non-conventional medicines share the commitment to broadcast knowledge of how to generate health, entailing studies on the sources of physical, psychological and spiritual health; they share the ethical and social mission to generate greater responsibility and social emancipation.

To produce evidence of NCM effectiveness, resources must obviously be channeled into quality research. It is paradoxical that the academic and institutional establishment should demand proof that NCM works when, with rare exceptions, no state funding is made over for the purpose.

Science stands in need of new paradigms of pluralism. That challenge for the future extends beyond biomedicine: we need to review the evidence-based approach and apply it to traditional and non-conventional medicine. Not only are the public health authorities still reticent about traditional and non-conventional medicine, the whole health system needs to set in motion a virtuous process whose central aim should be global care of the individual patient - person-centered medicine - a caring diachronic approach to the psycho-patho-biological human being. Ethics demand that we preserve, protect, promote, study, hand on and apply the cultural heritage of medical and anthropological health expertise, be it western or eastern, respecting the original integrity of the tradition paradigms and patrimonies. The epistemological status of medicine calls for reformulation, and the key to hand is "personcentered medicine".

Undoubtedly our present world is on the brink of an unusually complex and far-reaching change in the history of medicine and public health, extending to different yet interrelated facets of the system: the idea of health and disease, the importance of the individual's own perception of his health status; the concept of prevention and attention to lifestyle; awareness of forms of suffering and distress that lie outside organic disease as such; a new relationship between patient and doctor based on trust and collaboration, bringing out the person's inner resources so that he or she can face up to problems and make independent yet informed decisions as to behavior or treatment in keeping with personal health and lifestyle limitations; recognition that the best professional service is a combination of cognitive expertise, relating and communications skills and personal qualities; the relationship between citizen and health services; the phasing out of directional models in favor of a participatory approach giving the person their due, respecting their needs and upholding their free responsibility to choose the right treatment and improve their quality of life. A member of the public in the care of traditional and non-conventional medicine is not just an informed patient, but a competent and aware subject taking his life in hand [15-18].

In conclusion, medicine focused on the person results from the need of every patient and client and by providing a psychophysical balance to the individual, it is the steppingstone of any sustainable social balance for current and future societies. Person-centered medicine and non-conventional medicines represent a development of medical knowledge and practice. We call upon other scientific societies, academic institutions, and public organizations in the medical and healthcare field, for support and collaboration in building a person-centered medicine dedicated to the promotion of health as a state of physical, mental, social and spiritual wellbeing as well as to the reduction of disease, and founded on mutual respect for the dignity and responsibility of each individual person. We are keen to extend the focus of medicine from disease to patient to person by articulating science and humanism and gaining better insight into how the different dimensions of the personalized approach affect the process and outcome of care, and working respectfully with our patients towards every person's greater health and life's fulfilment.

Conflicts of interest None.

\section{References}

1. Maddalena S. Alternative medicines: on the way towards integration? A comparative legal analysis in western countries. Bern: Peter Lang; 2005.

2. Goldstein MS. The growing acceptance of complementary and alternative medicine. In: Bird CE, Conrad P, Fremont AM, editors. Handbook of medical sociology. New Jersey: Prentice Hall; 2000. p. 284-95.

3. Roberti di Sarsina P, Iseppato I. Looking for a Person-Centred Medicine: Non Conventional Medicine in the conventional 
European and Italian setting. Evid Based Complement Alternat Med. 2011. doi:10.1093/ecam/nep048.

4. Menniti-Ippolito F, Bologna E, Gargiulo L, Forcella E, Sabbadini LL, Raschetti R. Caratteristiche individuali e familiari degli utilizzatori di terapie non convenzionali in Italia. Ann Ist Super Sanità. 2004;40(4):455-61. Italian.

5. Roberti di Sarsina P, Iseppato I. CAM situation in Italy. Poster presentation. Inaugural scientific symposium: Complementary and Alternative Medicine: evidence for integration. New Haven: The Anlyan Center, Yale School of Medicine; 2008.

6. Roberti di Sarsina P, Iseppato I. Non Conventional Medicine in Italy: the present situation. EuJIM. 2009;1(2):65-71.

7. Roberti di Sarsina P. Le Medicine Non Convenzionali in Italia. La Medicina Biologica. 2009;1:29-34.

8. Roberti di Sarsina P, Iseppato I. State of art of the regulative situation of Non Conventional Medicines in Italy. J Alternat Complement Med. 2010;16(2):141-2.

9. Cocconi G, Caminiti C, Capriglia S, Gennari M, Minari R, Schianchi $\mathrm{P}$, et al. Attitudes to, and practice of, unconventional medicine by physicians in Italy. Eur J Intern Med. 2006;17:32-7.

10. Roberti di Sarsina P. 43rd National Congress of the Italian Psychiatric Association. Consensus conference: Non Conventional Medicines. Evid Based Complement Alternat Med. 2005;2(2):233-5.
11. Roberti di Sarsina P. The social demand for a medicine focused on the person: the contribution of CAM to healthcare and healthgenesis. Evid Based Complement Alternat Med. 2007;4(S1):45-51.

12. Roberti di Sarsina P. Le Medicine Non Convenzionali nel Programma d'Azione dell'Unione Europea in Materia di Salute: il Consorzio CAMbrella. La Medicina Biologica. 2010;2:2937.

13. Roberti di Sarsina P, Iseppato I. Person-Centred Medicine: towards a definition. Forsch Komplementmed. 2010;17:277-8.

14. Roberti di Sarsina P, Iseppato I. Why we need integrative medicine. EPMA J. 2011. doi:10.1007/s13167-011-0065-2.

15. Krumholz HM. Informed consent to promote patient-centered care. JAMA. 2010;303(12):1190-1.

16. Mezzich JE, Snaedal J, Van Weel C, Botbol M, Salloum I. Introduction to Person-Centred Medicine: from concepts to practice. J Eval Clin Pract. 2010. doi:10.1111/j.1365-2753.2010.01606.x.

17. Lee YY, Lin JL. Do patient autonomy preferences matter? Linking patient-centred care to patient-physician relationships and health outcomes. Soc Sci Med. 2010;71:1811-8.

18. Woolf SH, Dekker MM, Rothenberg Byrne F, Miller WD. Citizencentred health promotion. Building collaborations to facilitate healthy living. Am J Prev Med. 2011;40(1S1):S38-47. 